\title{
IMPLEMENTATION OF ELECTRONIC PRESCRIPTIONS: THE PHYSICIANS' VIEW
}

\author{
Kristina Drusany Starič ${ }^{1}$, Myra Tilney ${ }^{2}$, Ioanna Chouvarda ${ }^{3}$, Petra Bukovec ${ }^{4}$ and Hrvoje Belani ${ }^{5}$ \\ ${ }^{I}$ University medical centre Ljubljana, Division of gynaecology and obstetrics, Ljubljana, Slovenia \\ ${ }^{2}$ Faculty of Medicine and Surgery, Medical School, Mater Dei Hospital, Msida, Malta \\ ${ }^{3}$ Aristotle University of Thessaloniki, Faculty of Medicine, Medical Informatics and Biomedical Imaging Technologies \\ Thessaloníki, Greece \\ ${ }^{4}$ University medical centre Ljubljana, Division of surgery, Ljubljana, Slovenia \\ ${ }^{5}$ Ministry of Health, Independent Sector for IT and e-Health, Ksaver 200a, HR-10000 Zagreb, Croatia
}

\begin{abstract}
Connected Health is a paradigm shift looking after the individual and community health that is arising all over the world, applicable in a wide spectrum of care services, including primary care and electronic prescriptions (e-prescriptions), which are a core part of this ecosystem. Electronic prescribing has great potential as it reduces legibility problems associated with handwritten prescriptions, can automatically flag potential interactions, adverse effects improving patient safety and can facilitate operational pharmaceutical management including potentially reducing stock-outs. While e-prescriptions have been widely adopted, the manner of their application and monitoring needs further attention to optimize quality and reduce healthcare costs. The aim of this study was to investigate physicians' opinions on e-prescriptions their usage. The additional goal was to identify possible problems that might occur during the integration. Using a trusted online survey website, a brief questionnaire comprising of 10 multiple choice questions have been sent to 120 physicians through e-mail in thirteen different countries. Survey was conducted from October $1^{\text {st }}$ until December $18^{\text {th }} 2018$. As of December 2018, ninety-three questionnaires were complete and analysed. The survey showed that implementation of e-prescriptions is feasible. The time for writing e-prescriptions is not shortened comparing to handwritten prescriptions and the support system is not adequate. Nineteen (20\%) of the physicians lacked computer and e-prescribing skills. The use of e-prescriptions was more difficult for older physicians, the correlation between lower age and less needed time for e-prescribing was statistically significant $(\mathrm{P}<0.03)$. To increase its use, e-prescriptions users need to be informed how electronic health systems can be beneficial for the easier use of e-prescriptions. Adequate technical support and special training must be provided for older physicians, as they need more time for e prescribing.
\end{abstract}

\section{KEYWORDS}

e-Prescriptions, e-Prescribing, Connected Health, Older Physicians, Survey, e-Health

\section{INTRODUCTION}

Medication prescription for acute and chronic conditions is part of the process of rational treatment, as defined by World Health Organization (WHO). The process requires a logical, common sense approach and includes other components, such as specifying the therapeutic objective, and informing patients [de Vries et al.]. Electronic prescription (e-prescription) is the term for prescription of drugs, which is issued by an authorised professional person and is securely transmitted electronically to the pharmacy for dispensing [Leavitt], as illustrated on Figure 1. E-prescription is one part of the Connected Health that is the paradigm shift underpinning individual and community health in the health journey continuum of the person, through their lifespan, leveraging information technologies to produce a safe and effective treatment [ENJECT]. 


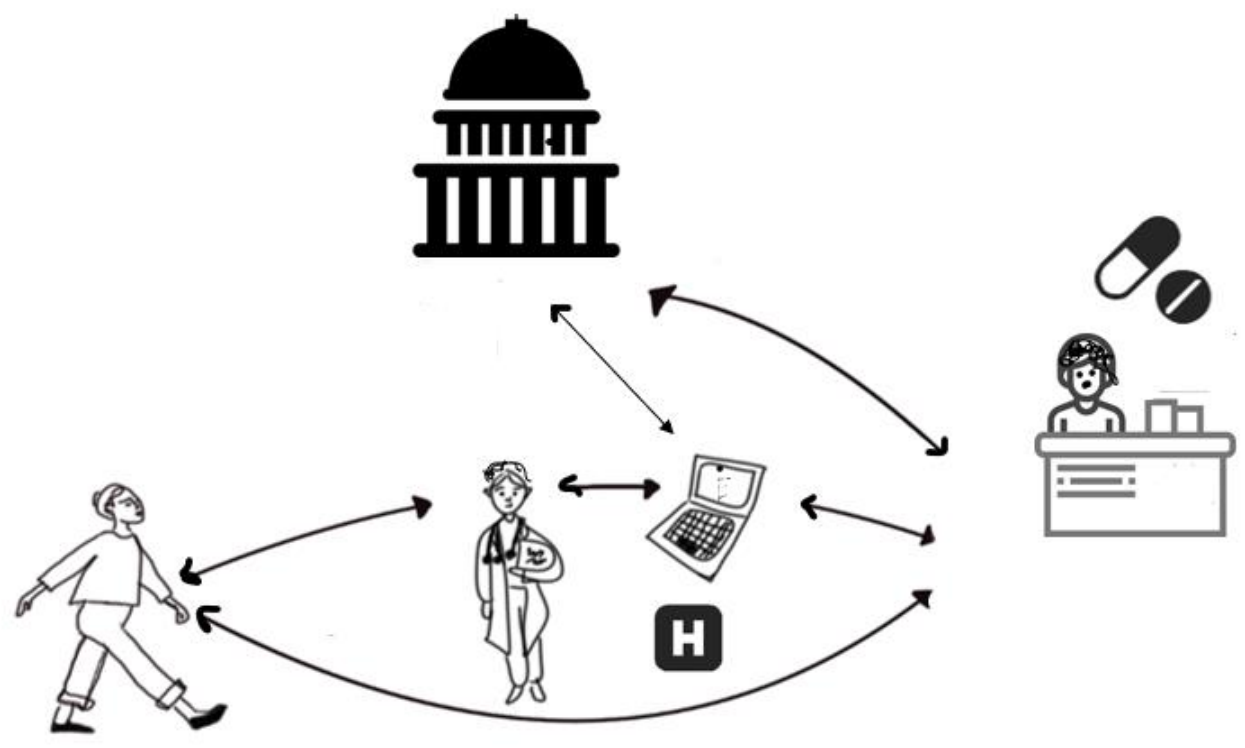

Figure 1. E-prescriptions is the term for electronically transmitted receipt for prescribed drugs prescribed by the physician in the cooperation with the patient to the pharmacist. The national institutions such as ministry of health and insurance companies regulate the process in all directions

E-prescribing is defined as a prescriber's ability to electronically send an accurate, error-free and understandable prescription directly to a pharmacy from the point-of-care. E-dispensing is defined as the act of electronically retrieving the prescription, and dispensing medications as indicated in the corresponding e-prescription. Once the medication has been dispensed, the system should also generate a report enabling monitoring of therapeutic adherence [Leavitt].

The potential benefits are multiple, ranging from reducing illegible prescriptions to facilitating real-time operational pharmaceutical management [Leavitt]. Depending on the level of clinical decision support available, potential interactions may be flagged, enhancing patient safety yet they can also potentiate error due to new process architecture [Gagnon et al.].

According to The Pharmaceutical Group of the European Union (PGEU), more than 160.000 pharmacies are computerised and have an internet connection for the daily usage of e-Health tools. These include dispensing e-prescribed medications, checking medication interactions, accessing electronic medication records, providing support for adherence via a mobile app or telephone call, or acting as the patient's entry point into the health system [Lyell et al.]. Not all medications can be e-prescribed, for example, narcotics and amphetamines, due to the potential for abuse, as well as safety aspects [Dhavle et al.]. As a result, despite appropriately regulatory framework for e-prescriptions, simultaneous manual prescriptions writing is required.

The main concern is the time required for the process of e-prescribing, which can greatly influence e-prescribing practice among different physicians. Another possible factor that may affect adoption of e-prescriptions is lower digital literacy in some health professionals [Dhavle et al.]. The e-prescribing can be time consuming especially for triplicates, as for narcotics and amphetamines prescriptions and potentially because of the repetition of the process, the problem may not only be the length of the process but also prescribing error can occur [PGEU].

To date, few studies mainly from North America and Europe have investigated the process of implementation of e-prescriptions [Gagnon et al.] [Lyell et al.] [Coleman et al.].

When a decision support system was introduced to aid the process of e-prescriptions, human factors were identified, like automation bias and reduced verification of medication alerts, which also contributed to prescribing errors [Kupperman et al.] [Kalantari and Fayaz-Bakhsh]. 
The aim of the study was to investigate European medical practitioners' perception of e-prescriptions. In moving from written to electronic prescriptions our research aimed to investigate physicians' use of e-prescriptions, the problems that might arise, to gain insight into the strengths and limitations, and to provide feedback, address error and facilitate streamlining the process. Our study addressed possible solutions for better e-prescribing.

\section{METHODS}

The authors who are physicians identified many problems during the period of transition to e- prescriptions at work. The problematics was discussed among authors and with their co-workers. Based on literature and findings of these discussions a questionnaire about e-prescribing was composed to obtain wider and non-biased view of the topic. The authors tested the validity of the questionnaire with establishment of face validity, the pilot test and clean the dataset. The questionnaire was given to the different non-medical professionals to review it. The questionnaire was then given to ten physicians to answer and evaluate the questions. Those were not the same physicians that were included in the survey and were not the authors of the questionnaire. After the testing of the survey questionnaire we did not remove any questions. The physicians included in the survey were from $13 \mathrm{EU}$ countries and every participant agreed to be included in the survey.

Using a trusted online survey website (SurveyMonkey, UK), a brief anonymous survey was devised and a link to it was e-mailed to 120 medical practitioners working in various specialities in hospitals from different European countries. The only criterion was to choose the physicians from the low- and high-income countries all over Europe, they were randomly chosen from available e-mail contacts of hospitals where authors work or have connections. From the e-mail lists of physicians, the authors have access to; a cluster sample was made as much as possibly representative of the European physicians working with prescriptions. We did not include the physicians that do not prescribe drugs like radiologists. We studied the possible differences between physicians before forming a questionnaire so general questions were used. The survey consisted of 10-multiple choice questions, which, at the discretion of the authors and our collaborators who also use e-prescriptions, summarize the opinion on the usefulness of e-prescriptions and their limitations. The survey was conducted from 1st October until 18th December 2018.

The registration of the study and ethical committee application were not applicable because it was anonymous and did not include patients. There were also no incentives offered.

The personal demographics (age, gender, and country of work), personal computer skills and e-prescriptions usage was addressed. Additional questions addressed experience with e-prescriptions, as well as an assessment of self-efficacy pertaining to personal computer skills, ability to prepare the computer for e-prescriptions, time required to use the system, whether they liked the system and their assessment of time consumption with e-prescriptions. We also asked about the possibility of error during e-prescribing and how well they think e-prescriptions could help to monitor prescribed drugs. A possible cause for reverting to the handwritten prescriptions was addressed. The survey structure with questions and answer options, as well as scale used for each of the ten questions, is given in Table 1.

Data analysis included descriptive statistics for each survey item and $\chi 2$ tests to compare the distribution of responses on categorical variables and their correlations. The results of descriptive statistics are given in absolute numbers and percentages in brackets. Statistical significance was set at $\mathrm{P}<0.05$. 
Table 1. Survey structure with questions and answer options

\begin{tabular}{|c|c|c|}
\hline Question & Answer option & Scale \\
\hline 1. What is your age? & $\begin{array}{c}18 \text { to } 24 \\
25 \text { to } 34 \\
35 \text { to } 44 \\
45 \text { to } 54 \\
55 \text { to } 64 \\
65 \text { to } 74 \\
75 \text { or older }\end{array}$ & Seven-point for belonging \\
\hline 2. In what country do you work? & $<$ all countries $>$ & One selection (drop-down) \\
\hline 3. What is your gender? & $\begin{array}{l}\text { Female } \\
\text { Male }\end{array}$ & $\begin{array}{r}\text { Dichotomous (two-point for } \\
\text { belonging) }\end{array}$ \\
\hline $\begin{array}{l}\text { 4. I think my computer skills are } \\
\text { sufficient for using a computer at } \\
\text { work: }\end{array}$ & $\begin{array}{l}\text { I strongly agree } \\
\text { I agree } \\
\text { I don't know } \\
\text { I disagree } \\
\text { I strongly } \\
\text { disagree }\end{array}$ & $\begin{array}{r}\text { Likert (five-point for } \\
\text { agreement) }\end{array}$ \\
\hline 5. I am using e-prescriptions: & $\begin{array}{l}\text { Yes, 5-10 years } \\
\text { Yes, 1-5 years } \\
\text { Yes, less than } 1 \\
\text { year } \\
\text { No }\end{array}$ & $\begin{array}{r}\text { Likert (four-point for } \\
\text { frequency) }\end{array}$ \\
\hline 6. I like e-prescriptions: & $\begin{array}{l}\text { Yes } \\
\text { Neutral } \\
\text { No }\end{array}$ & Three-point (yes-no-neutral) \\
\hline $\begin{array}{l}\text { 7. I can prepare the computer for e- } \\
\text { prescription easily: }\end{array}$ & $\begin{array}{l}\text { Yes, I can (I } \\
\text { am the only } \\
\text { one who is } \\
\text { using the } \\
\text { computer) } \\
\text { Yes, I can (I } \\
\text { am not the only } \\
\text { one who is } \\
\text { using the } \\
\text { computer) } \\
\text { No, I can't (I } \\
\text { am the only } \\
\text { one who is } \\
\text { using the } \\
\text { computer) } \\
\text { No, I can't (I } \\
\text { am not the only } \\
\text { one who is } \\
\text { using the } \\
\text { computer) }\end{array}$ & $\begin{array}{r}\text { Likert (four-point for } \\
\text { likelihood) }\end{array}$ \\
\hline $\begin{array}{l}8 . \text { I think e- prescriptions are time- } \\
\text { saving: }\end{array}$ & $\begin{array}{c}\text { I agree } \\
\text { I use the same } \\
\text { amount of time } \\
\text { I disagree }\end{array}$ & Three-point (yes-no-neutral) \\
\hline $\begin{array}{l}\text { 9. I think I make less mistakes with } \\
\text { prescriptions than with classical } \\
\text { prescriptions: }\end{array}$ & $\begin{array}{l}\text { Yes } \\
\text { Neutral } \\
\text { No }\end{array}$ & Three-point (yes-no-neutral) \\
\hline $\begin{array}{l}\text { 10. I think e-prescribed drugs are } \\
\text { more accurately monitored (e.g. two } \\
\text { different specialists cannot prescribs } \\
\text { the same drug at the same time): }\end{array}$ & $\begin{array}{l}\text { Yes } \\
\text { Neutral } \\
\text { No }\end{array}$ & Three-point (yes-no-neutral) \\
\hline
\end{tabular}




\section{RESULTS}

Hundred questionnaires were answered (83\%), of which $93(93 \%)$ were included in the study, as seven $(7 \%)$ were incomplete. Participants included 56 (60\%) female and 37 (40\%) male physicians. Participants were stratified by age range, with 25-34-year group comprising $46 \%(n=43)$, followed by the 35 to 44 years comprising $32(34 \%)$, 45-54 years 10 (11\%), six (6\%) from the 55-64-year range and just two (2\%) were from the '24 years and lower' age group. Age groups of the survey participants are given in Table 2. Participants were from 13 different European countries. Most participants came from Slovenia, Croatia and Malta. Distribution of the survey participants by country is given in Table 3.

Table 2. Age groups of survey participants

\begin{tabular}{|c|c|c|}
\hline Age & Count $(\mathrm{N})$ & Percentage $(\%)$ \\
\hline 24 years and less & 2 & $2 \%$ \\
\hline 25-34 years & 43 & $46 \%$ \\
\hline $35-44$ years & 32 & $34 \%$ \\
\hline $45-54$ years & 10 & $11 \%$ \\
\hline 55-64 years & 6 & $7 \%$ \\
\hline Total & 93 & $100 \%$ \\
\hline
\end{tabular}

Table 3. Distribution of survey participants by country

\begin{tabular}{lcr}
\hline Country & Count (N) & Percentage (\%) \\
\hline Austria & 2 & $2 \%$ \\
Bosnia and Herzegovina & 2 & $2 \%$ \\
Bulgaria & 1 & $1 \%$ \\
Croatia & 23 & $25 \%$ \\
Great Britain & 2 & $2 \%$ \\
Ireland & 1 & $1 \%$ \\
Italy & 5 & $5 \%$ \\
Malta & 10 & $11 \%$ \\
Norway & 1 & $1 \%$ \\
Portugal & 2 & $2 \%$ \\
Slovenia & 43 & $46 \%$ \\
Switzerland & 1 & $1 \%$ \\
Grand Total & $\mathbf{9 3}$ & $\mathbf{1 0 0 \%}$ \\
\hline
\end{tabular}

Most participants, 46 of them (49\%), considered the process of e-prescribing to be time saving, while 29 participants $(31 \%)$ disagree and eight participants $(9 \%)$ think the duration is like paper prescriptions. Ninety participants $(96 \%)$ consider themselves sufficiently computer-literate to provide e-prescriptions. According to this result, physicians' self-efficacy does not correlate with their perception for time-efficiency of e-prescriptions.

Participants duration of e-prescriptions usage were 5-10 years in 4\%, 1-5 years in 22\%, with $56 \%$ using it for under a year, and $18 \%$ stating that they are not using it. Survey participants' years of using e-prescriptions in given in Table 4.

Table 4. Survey participants' years of using e-prescriptions

\begin{tabular}{|c|c|c|}
\hline Years & Count $(\mathrm{N})$ & Percentage (\%) \\
\hline $6-10$ years & 4 & $4 \%$ \\
\hline $1-5$ years & 20 & $22 \%$ \\
\hline Less than 1 year & 52 & $56 \%$ \\
\hline Not using e-prescriptions & 17 & $18 \%$ \\
\hline Total & 93 & $100 \%$ \\
\hline
\end{tabular}

Fifty-five (59\%) responders like e-prescriptions, $12(13 \%)$ do not like them, $26(28 \%)$ are neutral. There is no significant difference in liking between physicians who are using e-prescriptions and those who do not.

Thirteen participants $(14 \%)$ have no subjective problems in computer usage and are not sharing their computer with co-workers - other medical professionals who also use e-prescriptions, 56 participants $(60 \%)$ can use computer without problems, and they share their computer with co-workers. Five $(5 \%)$ of them lack 
the appropriate computer skills for smoothly issuing e-prescriptions even though they have their own computers. Nineteen participants (20\%), who are sharing computer with other users, lack computer skills.

The opinions of physicians about the ability of the system to support error prevention are split: forty participants (43\%) think they make less mistakes with e-prescriptions, 10 participants (11\%) think that with e-prescriptions more mistakes occur and 43 participants (46\%) believe there is no difference regarding error prevention between handwritten prescriptions and e-prescriptions.

The majority, 69 participants (74\%) think the monitoring of drugs is better with e-prescriptions, while only seven participants (8\%) find it worse and 17 participants (18\%) think it is the same.

We did not notice any statistical difference in computer skills $(\mathrm{P}=0.72)$ and physicians liking of e-prescriptions $(\mathrm{P}=0.39)$ among different age groups. Only a correlation between with a lower age and less needed time for e-prescribing $(\mathrm{P}=0.03)$ was statistically significant. The data was presented in the table (see Multimedia Appendix 2).

\section{DISCUSSION}

The survey showed that implementation of e-prescriptions is feasible. The time for writing e-prescriptions is not shortened comparing to handwritten prescriptions and the support system is not adequate. The correlation between lower age of physicians and less needed time for e-prescribing was statistically significant.

Although various studies have investigated national perspectives, this study includes participants from various European regions enabling a more varied representation and overview of medical practitioners' view of e-prescriptions.

In our study, predominately women were involved. In 2014, there were 13 EU Member States where male physicians predominated, while 15 countries reported a higher share of female physicians. Because of the higher number of female physicians in 12 countries from which responses were obtained, the number of female responders was higher than male; alternatively, slightly biased [Eurostat]. The problem of the electronic literacy was described in 20\%, comparing to the study in Kuwait where the problems were in more than $50 \%$ [Almutairi et al.]. Results of this study revealed that $81.31 \%$ responders of the survey currently prescribe electronically. The number of users is different in different countries. The computer skills of the physicians are according to their perspective in $96 \%$ sufficient for use of e-prescriptions. The results show that most of them are using e-prescriptions less than a year, which indicates that the implementation is still in the process. One of the biggest problems of e-prescriptions is the support system (computer, other programs, user-unfriendly application) and the fact that only $74 \%$ of interviewed physicians believe that they can use the computer in order to write e-prescriptions, which is indicative of low ease of use. The physicians who are working in the wards are usually using multiple - not personal computers and that fore nonstop inscription of the usernames and passwords is necessary. In addition, end-users indicated that they were experiencing problems with authorisation procedures in a multi-user computer scenario but not if the computer was for solo usage. Despite many positive overall perceptions, they found that many e-prescribers reverted to handwritten prescriptions at least occasionally due to various reasons. For the minority of physicians (17\%), these difficulties resulted in abandoning the use of e-prescriptions altogether [Wang et al. 2009].

The study results demonstrate that $43 \%$ consider that the system reduces prescriptions error as compared to traditional prescribing, $74 \%$ consider that prescriptions duplication could be reduced by e-prescriptions of the drugs. The literature shows that patients had the same opinion [Cochran et al.]. Prevention strategies for diminishing errors should involve physicians as well as community pharmacists [Ryan et al.] [Fischer and Rose]. E-Prescriptions are not going to be abandoned. The improvements that fore need to be done [García Alfaro and Carballeira Rodríguez].

The older physicians need longer time to prescribe drugs electronically. In aging the skills and implementation of novelties takes more time, so the older physicians should have more support and special training [Meng et al.] [Wang et al. 2019]. In addition, the importance of learning as much computer skills as possible is very important for physicians in the future [Morton et al.].

Although various studies have investigated national perspectives [Kupperman et al.] [Ryan et al.], this study includes participants from various European regions enabling a more varied representation and overview of medical practitioners' view of e-prescriptions. Even though this study is one of the first such studies trying to establish an overview of the usefulness of e-prescriptions in some European countries, it also has its limitations. 
Firstly, we did not include every European country in the study and number of participants from some countries is low; the e-prescriptions could have also some minor differences between countries as well as in the support system. Furthermore, group of physicians that participated in the study were not completely randomly chosen, instead we sent the surveys to the random chosen colleagues from the email lists of hospitals where authors work or have connections. That may have introduced a bias, and therefore the results of this study cannot be conclusive as population opinion about e-prescriptions, but as opinion of a fragment of the people who answered the questionnaire. However, participation in the study was voluntary and for this reason, our sample may be biased toward physicians who are interested in this topic; hence, they may have been strong opponents or proponents of e-prescriptions. Clearly, these figures are not generalizable since they only represent the participant group. Apart from personal experience, differences in years of usage are also due to variation in year of introduction of e-prescriptions into the country, which varies from country to country.

\section{CONCLUSION}

The findings support the belief that many physicians are using e-prescriptions, as seen in Table 4 . The problem of preparing the computer and IT infrastructure, as well as time consumption needed for e-prescriptions, should be further addressed and improvements implemented. The results are strengthened by the fact that most e-prescriptions users in our sample had used their system for less than one year, which suggests that e-prescriptions are in the beginning of successful implementation once physicians learn how to use them. To increase its use, prescribers need to be informed how electronic health systems can be beneficial for the easier use of e-prescriptions. Special support and training should be provided for older physicians. We believe that, by addressing these issues will leverage the adoption and correct usage of e-prescriptions, they can better reach their potential to reduce medication error and prescriptions fraud, save time, and improve health care quality.

\section{ACKNOWLEDGEMENT}

This work has been supported by COST Action TD1405 - "European Network for the Joint Evaluation of Connected Health Technologies" (ENJECT) and COST Action CA16226 - "Indoor living space improvement: Smart Habitat for the Elderly" (SHELD-ON).

\section{REFERENCES}

Almutairi BA, Potts HWW, Al-Azmi SF, 2018. Physicians' Perceptions of Electronic Prescribing with Electronic Medical Records in Kuwaiti Primary Healthcare Centres. Sultan Qaboos Univ Med J. 2018 Nov;18(4):e476-e482. Mar 28. PMID: 30988966; PMCID: PMC6443264. [Medline]

Cochran GL, Lander L, Morien M, Lomelin DE, Brittin J, Reker C, Klepser DG, 2015. Consumer Opinions of Health Information Exchange, e-Prescribing, and Personal Health Records. Perspect Health Inf Manag. 2015 Nov 1; 12 (Fall):1e. PMID: 26604874; PMCID: PMC4632874. [Medline]

Coleman JJ, Hodson J, Thomas SK, Brooks HL, Ferner RE, 2015. Temporal and other factors that influence the time doctors take to prescribe using an electronic prescribing system. J Am Med Inform Assoc. 2015 Jan;22(1):206-12: 25074989; PMCID: PMC4433371. [Medline]

Dhavle AA, Ward-Charlerie S, Rupp MT, Kilbourne J, Amin VP, Ruiz J, 2016. Evaluating the implementation of RxNorm in ambulatory electronic prescriptions. J Am Med Inform Assoc. 2016 Apr;23(e1):e99-e107. Epub 2015 Oct 28. PMID: 26510879; PMCID: PMC4954631. [Medline]

ENJECT, 2016. http://enject.eu/connected-health-defined-at-enject-porto-workshop/ [accessed 2019-09-09]

Eurostat, 2017. Healthcare personnel statistics - physicians. Retrieved from http://ec.europa.eu/eurostat/statisticsexplained/index.php/Healthcare_personnel_statistics_-_physicians [accessed 2019-04-04]

Fischer S, Rose A, 2017. Responsible e-Prescribing Needs e-Discontinuation. JAMA, 317(5), 469. doi:10.1001/jama.2016.19908 PMID: 28170486 [Medline] 
Gagnon MP, Nsangou ÉR, Payne-Gagnon J, Grenier S, Sicotte C., 2014. Barriers and facilitators to implementing electronic prescription: a systematic review of user groups' perceptions. J Am Med Inform Assoc. 2014 May-Jun;21(3):535-41. PMID: 24130232; PMCID: PMC3994867. [Medline]

García Alfaro I, Carballeira Rodríguez JD, 2019. Electronic prescription: limitations and possible improvements to ensure greater adherence to treatments. Rev Esp Salud Publica. 2019 Sep 25;93. [Medline]

Kalantari E, Fayaz-Bakhsh A, 2012. Can an electronic prescribing system detect doctors who are more likely to make a serious prescribing error? J R Soc Med. 2012 May;105(5):191. PMID: 22637768; PMCID: PMC3360530. [Medline]

Kupperman E, Vigil D, Yazdani A, Baldwin K, 2016. Model of Current Practice Regarding Prescriptions of Controlled Substances and the Perceived Benefits of E-Prescribing in an Academic Medical Center. J Med Syst. 2016 Dec;40(12):278. [Medline]

Leavitt MO, 2014. The centers for medicare and medicaid service (CMS). US Congress Report, USA. https://www.cms.gov/Medicare/E-Health/Eprescribing/Downloads/E-RxReporttoCongress.pdf [accessed 2019-09-09]

Lyell D, Magrabi F, Raban MZ, Pont LG, Baysari MT, Day RO, Coiera E, 2017. Automation bias in electronic prescribing. BMC Med Inform Decis Mak. 2017 Mar 16;17(1):28. PMID: 28302112; PMCID: PMC5356416. [Medline]

Meng X, Li G, Jia Y, Liu Y, Shang B, Liu P, Bao X, Chen, 2019. Effects of dance intervention on global cognition, executive function and memory of older adults: a meta-analysis and systematic review. Aging Clinical and Experimental Research. 2019 Apr 13 [Medline]

Morton CE, Smith SF, Lwin T, George M, Williams M, 2019. Computer Programming: Should Medical Students Be Learning It? JMIR Med Educ. 2019 Mar 22;5(1):e11940. doi: 10.2196/11940. PMID: 30901000; PMCID: PMC6450476. [Medline]

PGEU - Pharmaceutical Group of European Union, 2016. PGEU Statement: eHealth Solutions in European Community Pharmacies.

Ryan C, O'Mahony D, Kennedy J, Weedle P, Byrne S, 2009. Potentially inappropriate prescribing in an Irish elderly population in primary care. Br J Clin Pharmacol. 2009 Dec;68(6):936-47. PMID: 20002089; PMCID: PMC2810806. [Medline]

de Vries TPGM, Henning RH, Hogerzeil HV, Fresle DA, 1994. Action Programme on Essential Drugs: Guide to Good Prescribing - A Practical Manual. World Health Organization (WHO), Geneva, pp. 115. URL: http://apps.who.int/medicinedocs/pdf/whozip23e/whozip23e.pdf [accessed 2019-09-09]

Wang S, Bolling K, Mao W, Reichstadt J, Jeste D, Kim HC, Nebeker C, 2019. Technology to Support Aging in Place: Older Adults' Perspectives. Healthcare (Basel). 2019 Apr 10;7(2):60. doi: 10.3390/healthcare7020060. PMID: 30974780; PMCID: PMC6627975. [Medline]

Wang CJ, Patel MH, Schueth AJ, Bradley M, Wu S, Crosson JC, Glassman PA, Bell DS, 2009. Perceptions of standards-based electronic prescribing systems as implemented in outpatient primary care: a physician survey. $J \mathrm{Am}$ Med Inform Assoc. 2009 Jul-Aug;16(4):493-502. PMID: 19390106; PMCID: PMC2705252. [Medline] 